\title{
Chromosome study of Anteaters (Myrmecophagideae, Xenarthra) - A preliminary report
}

\author{
Hélio Rubens Jacintho Pereira Júnior ${ }^{1,2}$, Wilham Jorge ${ }^{2}$ and Maria Elvira Loyola Teixeira da Costa ${ }^{3}$ \\ ${ }^{1}$ Universidade Estadual Paulista, Instituto de Biociências de Botucatu, Botucatu, SP, Brazil. \\ ${ }^{2}$ Universidade Federal de Minas Gerais, Departamento de Biologia Geral, Laboratório de Citogenética, \\ Belo Horizonte, $M G$, Brazil. \\ ${ }^{3}$ Fundação Zoobotânica de Belo Horizonte, Belo Horizonte, MG, Brazil.
}

\begin{abstract}
Anteaters belong to the Order Xenarthra / Family Myrmecophagidae and are the only members without teeth. There are three genera with four living species in the family Myrmecophagidae: Myrmecophaga tridactyla (giant anteater), Tamandua tetradactyla (southern lesser anteater), Tamandua mexicana (northern lesser anteater), and Cyclopes didactylus (silky anteater). The karyotypes of $M$. tridactyla $(2 n=60)$, T. tetradactyla $(2 n=54)$ and $C$. didactylus $(2 n=64)$ have already been described. In the present paper, three female and two male specimens of giant anteater and one lesser anteater male were analyzed. The results indicate the existence of a new karyotype in the genus Tamandua, with $2 n=56$ chromosomes, which can represent a new lesser anteater species. The karyotype of $M$. tridactyla was also described, supporting previous reports.
\end{abstract}

Key words: Anteater, chromosomes, Myrmecophagidae.

Received: July 7, 2003; Accepted: February 2, 2004.

\section{Introduction}

The Order Xenarthra comprises three living groups: anteaters, armadillos and tree sloths. These animals are found from the south-central and southeastern United States to southern South America (Nowak, 1999; Wetzel, 1985). This order is composed of thirty living species, divided into four families: Dasypodidae (armadillos), Myrmecophagidae (anteaters), Bradypodidae (three-toed sloths), and Megalonychidae (two-toed sloths) (Wetzel, 1985). The species Priodontes maximus (giant armadillo), Tolypeutes tricinctus (Brazilian three-banded armadillo), Bradypus torquatus (collared sloth) and Myrmecophaga tridactyla (giant anteater) are classified as vulnerable by the IUCN (International Union for Conservation of Nature). Collared sloths and the Brazilian three-banded armadillo are endemic in Brazil. A high degree of anatomical and physiological modifications for feeding purposes is found in the family Myrmecophagidae: the muzzle is tubular, strait and long, ending with a small mouth about $20 \mathrm{~mm}$ in diameter, and most of the facial musculature is reduced (Naples, 1999). A viscous and adherent mucus is produced

Send correspondence to Wilham Jorge. Fundação Zoobotânica de Belo Horizonte, Rua Carrara 111, Bairro Bandeirantes, 31340-710 Belo Horizonte, MG, Brazil. E-mail: wiljorge @icb.ufmg.br. in the elongated sticky tongue, which helps to capture ants and termites (Naples, 1999).

Most xenarthrans have a karyotypic constitution that varies from $2 \mathrm{n}=48$ to $2 \mathrm{n}=65$ chromosomes, except for Tolypeutes matacus, with $2 \mathrm{n}=38$ chromosomes (Jorge et al., 1977). Of the thirty species known to date, only nineteen had their karyotypes described or reported. The karyotypes of the family Myrmecophagidae vary between $2 \mathrm{n}=$ 54 and $2 n=64$. A remarkable difference in karyotypes exists between Cyclopes didactylus $(2 \mathrm{n}=64)$ and other species of the family Myrmecophagidae (Jorge et al., 1985a). A mechanism of reversible fusion/fission and reciprocal translocation was proposed by Jorge et al. (1985b) to explain the reduction in chromosome number from 64 to 54 in Tamandua and Myrmecophaga, respectively. The karyotype of Tamandua tetradactyla was described by Hsu (1965), although illustrations of the chromosomes were not available. The G-banded karyotype was described by Jorge et al. (1977). According to Hsu (1965), although their chromosomes are very similar, these two species have phenotypic differences, especially regarding the body size and weight of $T$. longicaudata, which are greater than those of T. tetradactyla. However, Wetzel $(1975,1985)$ described a distribution of Tamandua species displaying several variations in coat colors from southern Mexico to 
northern Argentina and Uruguay. Wetzel (1975) considered the genus Tamandua as comprising two species, $T$. tetradactyla (the black-vested form) and T. longicaudata (Wagner) (lacking a complete vest), or only one species: $T$. tetradactyla, subdivided into three subspecies: the nonvested or partially vested T. tetradactyla longicaudata, and the melanistic forms T. tetradactyla nigra (Geoffroy), and T. tetradactyla quichua (Thomas). Moreover, Wetzel (1985) considered that there were four species in the family Myrmecophagidae: Cyclopes didactylus, Myrmecophaga tridactyla, Tamandua mexicana, and Tamandua tetradactyla.

The purpose of this study was to describe the karyotype of a lesser anteater species and of five specimens of giant anteaters, all from southeastern Brazil. The reduction in chromosome number of Myrmecophagidae is also discussed.

\section{Material and Methods}

In the present work, three female and two male specimens of Myrmecophaga tridactyla (giant anteater) and one male of the genus Tamandua (lesser anteater) were studied. The animals belonged to the Zoological Garden of Belo Horizonte, Minas Gerais, Brazil. Two female and one male giant anteaters were born in the Zoo. The lesser anteater was found in the coastal region of the Atlantic Rainforest in São Paulo State, Brazil. From each animal $10 \mathrm{~mL}$ of whole blood were collected, using heparin. Leukocyte cultures were prepared from whole blood, using phytohemagglutinin as a stimulant for cell division, incubated at $37{ }^{\circ} \mathrm{C}$ for $72 \mathrm{~h}$, followed by colchicine or colcemid and hypotonic treatment.

\section{Results and Discussion}

The cytogenetic analysis of the animals studied showed the following karyotypic constitutions: $2 n=56$ with a new karyotype in one specimen of the genus Tamandua (Figure 1 and Table 1), and 2n= 60 chromosomes in $M$. tridactyla ,as reported by Hsu (1965) (Figure 2 and Table 1). Distinct karyotypic patterns are established in this paper for the family Myrmecophagidae: Tamandua tetradactyla (southern lesser anteater), with $2 \mathrm{n}=54$ chromosomes (Hsu, 1965; Hsu and Benirschke, 1969; Jorge et al., 1977), has the smallest number of chromosomes in the family Myrmecophagidae. Until 1975, the species T. tetradactyla was separated into two species: T. tetradactyla (Linné, 1758, in Wetzel, 1975) and T. longicaudata (Wagner, 1844, in Wetzel, 1975). Wetzel (1975) analyzed morphological characters such as cranial structure and showed that both species could be considered as a single one, denominated $T$. tetradactyla.

Hsu (1965) described the karyotype of T. tetradactyla (from Mexico), and Jorge et al. (1977) described the karyotype of $T$. longicaudata (from Colombia), both with

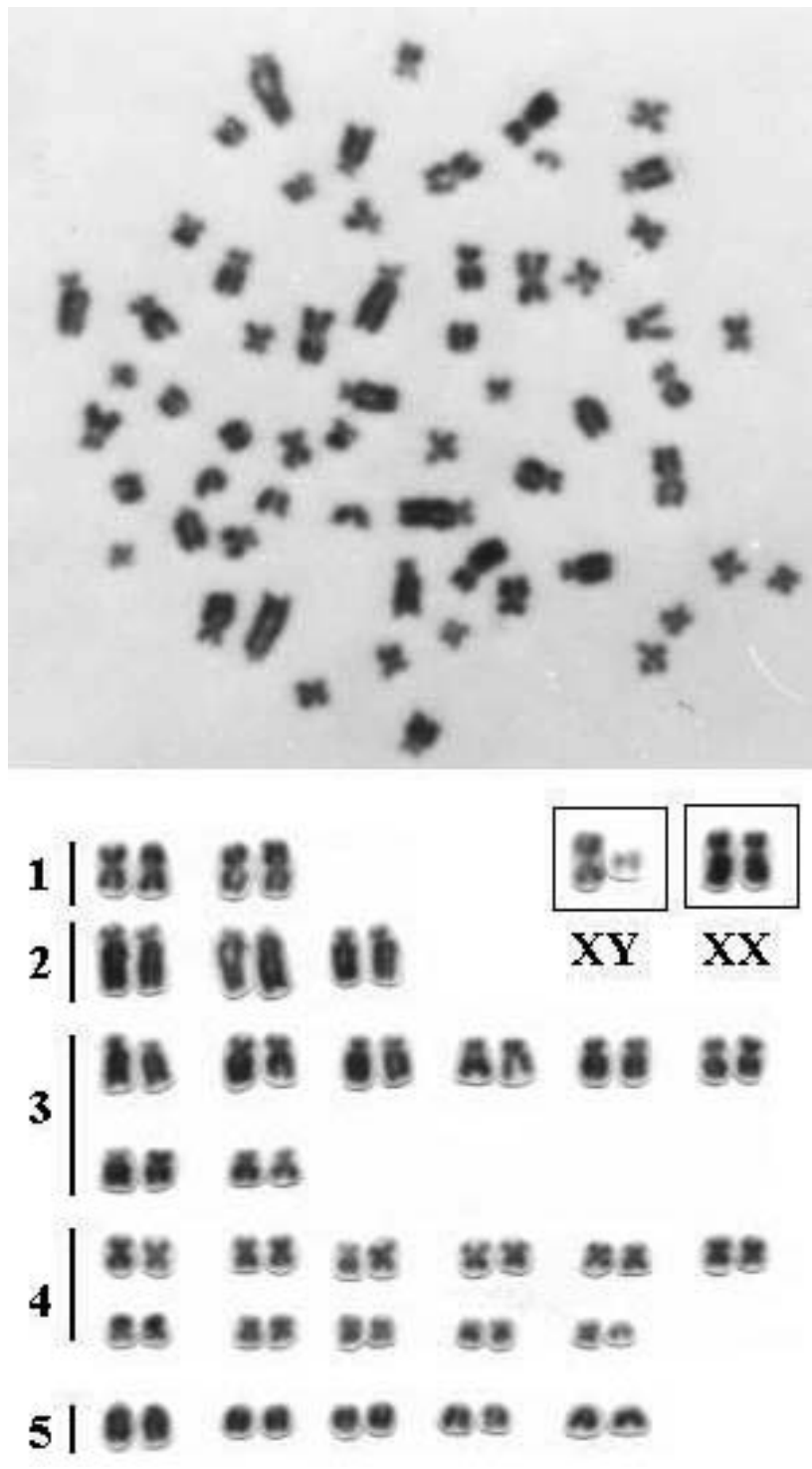

Figure 1 - Karyotype of Tamandua $s p$. with $2 \mathrm{n}=56$ chromosomes. The $\mathrm{X}$ chromosome is a large metacentric, and the $\mathrm{Y}$ chromosome is a small acrocentric.

$2 \mathrm{n}=54$ chromosomes. The results of these chromosome analyses corroborate the results of geographical distribution studies, weight and size, as well as of other data on body morphology obtained by Wetzel (1975). The karyotype of the genus Tamandua does not exhibit acrocentric chromosomes, except for the Y chromosome. T. tetradactyla has four pairs of large metacentric chromosomes, while Tamandua sp. has three pairs in group I (Figure 1 and Table 2). Group II is composed of three pairs of large submetacentric chromosomes that are constant for both species. Group III exhibits seven pairs of mediumsized submetacentrics in $T$. tetradactyla and nine submetacentrics in Tamandua sp. Group IV is formed by twelve pairs of metacentrics, from medium to small in size. The $\mathrm{X}$ chromosome is a large metacentric, with a size 
Table 1 - Chromosome constitution of the anteaters analyzed in this study, according to diploid number, number of pairs per group and chromosome morphology.

\begin{tabular}{lccl}
\hline $\begin{array}{l}\text { Species / } \\
\text { Diploid number }\end{array}$ & Group & $\begin{array}{c}\text { Number of } \\
\text { pairs }\end{array}$ & Chromosome morphology \\
\hline $\begin{array}{lccl}\text { Tamandua } \\
\text { 2n }=56\end{array}$ & I & 03 & large metacentrric \\
& II & 03 & large submetacentric \\
& III & 09 & medium submetacentric \\
& IV & 12 & medium to small \\
& Sex & $\mathrm{X}$ & large metacentric \\
& Sex & Y & small acrocentric \\
\hline $\begin{array}{l}\text { Myrmecophaga } \\
\text { tridactyla }\end{array}$ & I & 02 & large metacentric \\
$2 \mathrm{n}=60$ & II & 03 & large submetacentric \\
& II & 08 & medium submetacentric \\
& IV & 11 & medium to small \\
& & & metacentric \\
& V & 05 & Acrocentric \\
& Sex & $\mathrm{X}$ & large metacentric \\
& Sex & Y & small acrocentric \\
\hline
\end{tabular}

equivalent to the third pair of autosomes in both species. The $\mathrm{Y}$ chromosome is a small acrocentric. The difference between both species is basically the number of chromosomes in groups I and III. This difference may be explained by the fusion process: two pairs of group III of the species with $2 \mathrm{n}=56$ would originate the extra pair in group I of the species with $2 \mathrm{n}=54$, as well as an additional structural chromosome rearrangement. In the species with $2 n=56$, most autosomes are small-sized metacentrics, probably arisen from the fusion of acrocentrics, which are also found in other genera of this family. The presence of a fourth metacentric pair $(2 n=54)$ can be explained by the fusion of two pairs of submetacentrics present in the karyotype with $2 \mathrm{n}=56$, followed by a loss of chromosome material.

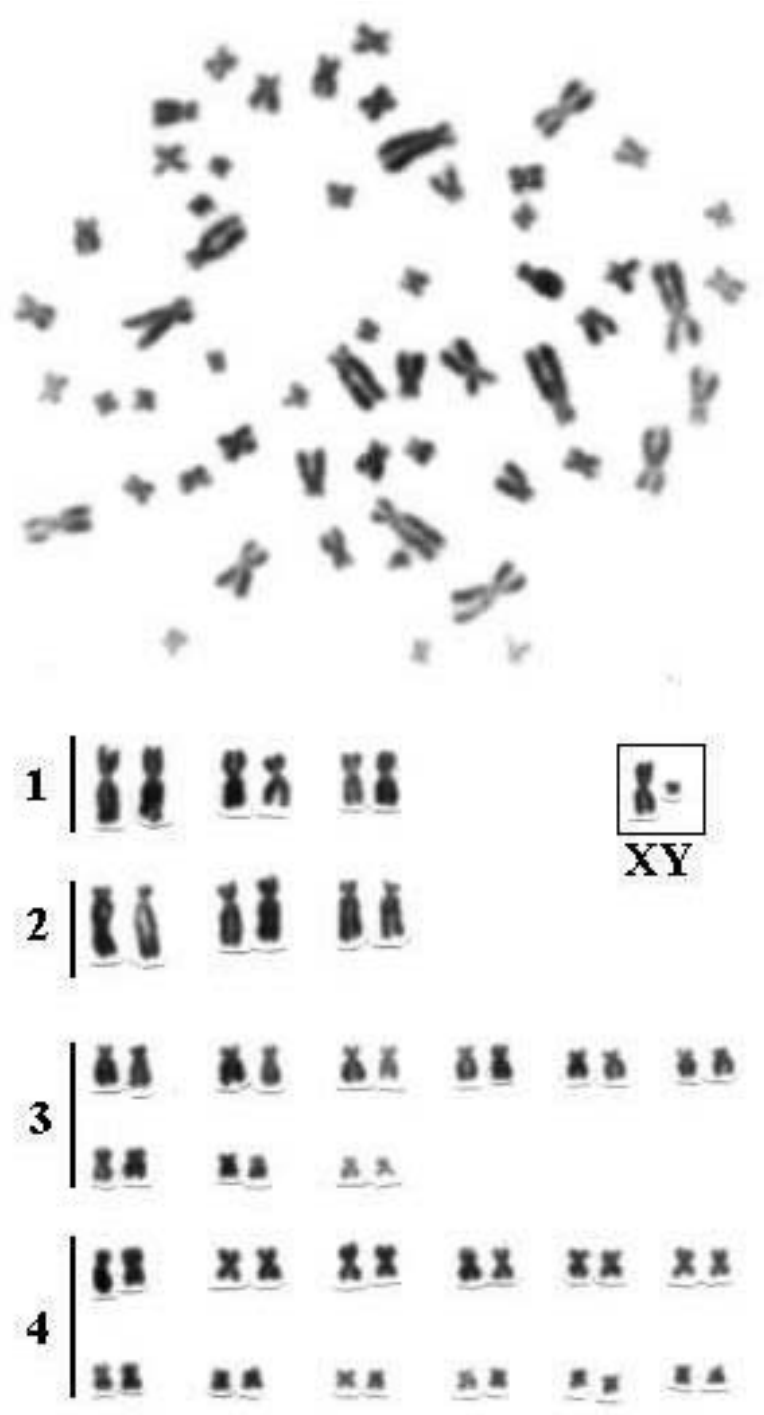

Figure 2 - Karyotype of Myrmecophaga tridactyla with $2 \mathrm{n}=60$ chromosomes showing the $\mathrm{X}$ and $\mathrm{Y}$ chromosome morphology. The two $\mathrm{X}$ chromosomes of a female are exhibited in the karyotype.

Table 2 - Karyotypes of anteater species, according to Wetzel (1985) and Nowak (1999).

\begin{tabular}{|c|c|c|c|c|c|c|}
\hline Species & Collection sites & Sex & $2 n$ & $\mathrm{X}$ & $\mathrm{Y}$ & References \\
\hline \multirow{3}{*}{$\begin{array}{l}\text { Tamandua } \\
\text { tetradactyla }\end{array}$} & Philadephia Zoo, U.S.A. & M & 54 & third pair & Small submetacentric & Hsu and Benirschke (1969) \\
\hline & Colombia & $\mathrm{F}$ & 54 & submetacentric & Unknown & Jorge et al. (1977) \\
\hline & Chiapas, México & $\mathrm{F}$ & 54 & unknown & Unknown & Hsu (1965) \\
\hline \multirow[t]{3}{*}{$\begin{array}{l}\text { Cyclopes } \\
\text { didactylus }\end{array}$} & $\begin{array}{l}\text { Japurá River, Amazonas } \\
\text { State, Brazil }\end{array}$ & $\mathrm{F}$ & 64 & unknown & Unknown & Jorge et al. (1985a) \\
\hline & $\begin{array}{l}\text { Manaus, Amazonas } \\
\text { State, Brazil }\end{array}$ & M & 64 & $\begin{array}{l}\text { third pair } \\
\text { submetacentric }\end{array}$ & Smallest chromosome & Jorge (2000) \\
\hline & $\begin{array}{l}\text { Manaus, Amazonas } \\
\text { State, Brazil }\end{array}$ & $\mathrm{F}$ & 64 & & & \\
\hline \multirow{3}{*}{$\begin{array}{l}\text { Myrmecophaga } \\
\text { tridactyla }\end{array}$} & Herman Park Zoo & $\mathrm{F}$ & 60 & unknown & Unknown & Hsu (1965) \\
\hline & \multirow{2}{*}{$\begin{array}{l}\text { Fundação Zoobotânica / } \\
\text { MG }\end{array}$} & $\mathrm{F}$ & 60 & third pair metacentric & Acrocentric & Present paper \\
\hline & & M & 60 & & & \\
\hline Tamandua sp. & $\begin{array}{l}\text { Atlantic Rainforest - } \\
\text { São Paulo State, Brazil }\end{array}$ & M & 56 & third pair metacentric & Acrocentric & Present paper \\
\hline
\end{tabular}


In the present work, the existence of a new karyotype in the genus Tamandua is evident. This may represent a new species, different from those previously described by Hsu (1965) and Jorge et al. (1977). This new species is bigger in weight and size and is different from Tamandua mexicana (whose karyotype has not yet been described).

Regarding the giant anteater (M. tridactyla), Hsu (1965) found $2 \mathrm{n}=60$ chromosomes (Table 2), which is confirmed in the present work (Figure 2). This species has an extra group of acrocentrics (group V), as compared to the species described previously. The $\mathrm{X}$ chromosome is metacentric and has the same size as the third pair of group $\mathrm{I}$, and the $\mathrm{Y}$ is the smallest chromosome of all.

As for the silky anteater (Cyclopes didactylus), whose karyotype was described by Jorge et al. (1985b) and Jorge (2000), it has the largest diploid number in the family Myrmecophagidae, $2 \mathrm{n}=64$ (Table 2) and a greater total number of acrocentrics. The data obtained by molecular analysis (Delsuc et al., 2001; Delsuc et al., 2002; Barros et al., 2003) indicate that the genus Cyclopes diverged from the genera Tamandua and Myrmecophaga about 33 MYA. The reduction of the diploid number by fusion of acrocentrics seems to be a tendency in this family. Detailed cytogenetic studies of the species from different parts of America regarding body size, weight and color are necessary in order to characterize the species with respect to chromosome structure.

\section{Acknowledgements}

The authors thank "Fundação Zoobotânica de Belo Horizonte / MG" for allowing them to collect animal material and also CAPES and CNPq (Process 471485 / 01-2) for supporting this study. This work was licensed by IBAMA (177/02 - "Fauna / MG").

\section{References}

Barros MC, Sampaio I and Schneider H (2003) Phylogenetic analysis of 16S mitochondrial DNA data in sloths and anteaters. Genetics and Molecular Biology 26:5-12.

Delsuc F, Scally M, Madsen O, Stanhope MJ, Jong WW, Catzeflis FM, Springer MS and Douzery EJP (2002) Molecular phylogeny of living xenarthrans and the impact of character and taxon sampling on the placental tree rooting. Mol Biol Evol 19:1656-1671.

Delsuc F, Catzeflis FM, Stanhope MJ and Douzery EJP (2001) The evolution of armadillos, anteaters and sloths depicted by nuclear and mitochondrial phylogenies: implications for the status of the enigmatic fossil Eurotamandua. Proc R Soc Lond 268:1605-1615.

Hsu TC (1965) Chromosomes of two species of anteaters. Mammalian Chromosomes Newsletter 15:108.

Hsu TC and Bernirschke K (1969) Tamandua tetradactyla. An Atlas of Mammalian Chromosomes 3:108.

IUCN (2002) Red List of Threatened Species 2002. Extract for http://www.redlist.org/ in April of 2003.

Jorge W (2000) Mitotic and meiotic chromosome studies in silky anteater Cyclopes didactylus (Myrmecophagidae: Xenarthra). Cytobios 101:95-100.

Jorge W, Best RC and Wetzel RM (1985a) Chromosome studies on the silky anteater Cyclopes didactylus L. (Myrmecophagidae: Xenarthra, Edentata). Caryologia 38:325-329.

Jorge W, Orsi-Souza AT and Best RC (1985b) The somatic chromosomes of Xenarthra. In: Montgomery GG (ed) The Evolution and Ecology of Armadillos, Sloths and Vermilinguas. Smithsonian Institution Press, Washington and London, pp 121-129.

Jorge W, Meritt DA and Bernirschke K. (1977) Chromosome studies in Edentata. Cytobios 18:157-172.

Naples VL (1999) Morphology, evolution and function of feeding in the giant anteaters (Myrmecophaga tridactyla). J Zool Lond 249:19-41.

Nowak RM (1999) Walkers Mammals of the World. 6th edition. The Johns Hopkins University Press, Baltimore and London, pp 147-168.

Wagner JA (1844) Die Säugetiere in Abbildungen nach der Natur mit Bescheibungen von Dr. Johann Christian Daniel von Schereber. Suppl. In: Wetzel RM (1975) The species of Tamandua Gray (Edentata, Myrmecophagidae). Proceedings of the Biological Society of Washington 88:95-112.

Wetzel RM (1975) The species of Tamandua Gray (Edentata, Myrmecophagidae). Proceedings of the Biological Society of Washington 88:95-112.

Wetzel RM (1985) The identification and distribution of recent Xenarthra (=Edentata). In: Montgomery GG (ed). The Evolution and Ecology of Armadillos, Sloths and Vermilinguas. Smithsonian Institution Press, Washington and London, pp 5-21. 